\title{
Prevalence of cardio-respiratory factors in the occurrence of the decrease in oxygen uptake during supra-maximal, constant-power exercise
}

\author{
Christine Hanon $^{1 *}$, Sylvain Dorel ${ }^{1,2}$, Rémi Delfour-Peyrethon ${ }^{1,2}$, Pierre-Marie Leprêtre ${ }^{3}$, David J Bishop ${ }^{5}$, \\ Stéphane Perrey ${ }^{4}$ and Claire Thomas ${ }^{1,6}$
}

\begin{abstract}
Purpose: To investigate the physiological mechanisms that explain the end-exercise decrease in oxygen uptake $\left(\dot{V} \mathrm{O}_{2}\right)$ during strenuous constant-power exercise, we recruited eleven trained, track cyclists.

Methods: On two separated days they performed 1) resting spirometric measures, followed by an incremental test on a cycle ergometer to determine the power output at $\dot{\mathrm{V}} \mathrm{O}_{2 \max }\left(\mathrm{P}-\dot{\mathrm{V}} \mathrm{O}_{2 \max }\right)$ and 2) an exhaustive isokinetic supramaximal cycling exercise (Tlim supra $_{\text {) }}$ at $185 \pm 24 \%$ of $\mathrm{P}-\dot{\mathrm{V}} \mathrm{O}_{2 \max }$ (i.e., $640.5 \pm 50.8 \mathrm{~W}$ ). During cycling exercise tests, $\dot{V} \mathrm{O}_{2}$, ventilation parameters, stroke volume (SV) and heart rate were continuously recorded. Furthermore, arterialised capillary blood samples were collected to measure blood pH, arterial oxygen saturation, lactate and bicarbonate concentration before and 5 min after Tlimsupra.

Results: $\mathrm{A}>5 \%$ decrease in $\dot{\mathrm{V}} \mathrm{O}_{2}$ and/or SV was observed in 6 subjects, with 5 out of 6 subjects presenting both phenomena. The magnitude of the $\dot{V} \mathrm{O}_{2}$ decrease was correlated with the magnitude of the SV decrease $(\mathrm{R}=0.75$, $P<0.01)$, the peak-exercise end-tidal $\mathrm{O}_{2}$ partial pressure $(R=0.80, P<0.005)$ and the resting, forced expiratory volume in $1 \mathrm{~s}(\mathrm{R}=0.72, \mathrm{P}<0.05)$, but not with any blood variables. The significant post-Tlim supra $_{\text {a }}$ decrease in forced vital capacity and forced inspiratory volume corroborate with a possible respiratory muscle fatigue.

Conclusion: Based on these findings, we demonstrate that the occurrence of $\dot{V} \mathrm{O}_{2}$ decrease in more than half of our subjects, during a strenuous constant-power exercise leading to a mild-acidosis $(\mathrm{pH}=7.21 \pm 0.04)$, results mainly from cardio-respiratory factors and not from blood metabolic responses.
\end{abstract}

Keywords: High-intensity exercise; Oxygen consumption; Acidosis; Cardio-respiratory parameters

\section{Background}

A significant decrease in whole-body pulmonary oxygen uptake $\left(\dot{V} \mathrm{O}_{2}\right)$ at the end of supra-maximal running exercise in the field has been reported (Billat et al. 2009, Hanon et al. 2010; Thomas et al. 2005). Of note, the $\dot{V}$ $\mathrm{O}_{2}$ decrease was concomitant with a decrease in running velocity that could logically be considered as one of the explanations for this phenomenon. However, it is important to note that (i) the $\dot{V} \mathrm{O}_{2}$ decrease was proportionally larger than the drop in running velocity (Hanon and Thomas 2011) and (ii) the final velocity was always

\footnotetext{
* Correspondence: christine.hanon@insep.fr

${ }^{1}$ French National Institute of Sports (INSEP), Research Department, Laboratory of Sport, Expertise and Performance, 11 Tremblay Avenue, 75012 Paris, France Full list of author information is available at the end of the article
}

greater than the velocity associated with the maximal $\dot{V}$ $\mathrm{O}_{2}\left(\dot{\mathrm{V}}_{2 \max }\right)$ of each subject (Hanon and Thomas 2011). Additionally, researchers have also observed a $\dot{V} \mathrm{O}_{2}$ decrease during exhaustive treadmill exercise performed at a constant intensity (Nummela and Rusko 1995), (Perrey et al. 2002). An important unresolved physiological question therefore, is what are the mechanisms that contribute to this phenomenon?

Gathering their 400-, 800- and 1500-m data, Hanon et al. (Hanon and Thomas 2011), established correlations between the peak blood lactate concentration ([La] $)(\mathrm{R}=0.55, \mathrm{P}<0.05)$ and the magnitude of the $\dot{V} \mathrm{O}_{2}$ decrease, and between the 300-m intermediate $\mathrm{pH}$ value and the 400-m final $\dot{V} \mathrm{O}_{2}(\mathrm{R}=0.86)$ (Hanon et al. 2010). 
Low blood $\mathrm{pH}$ values reduce the affinity of $\mathrm{O}_{2}$ to haemoglobin and contribute to an exercise-induced arterial hypoxemia (EIAH). Harms et al. (Harms et al. 2000) stated that $\dot{V} \mathrm{O}_{2}$ appears to decrease by $2 \%$ for each $1 \%$ decrease of arterial $\mathrm{O}_{2}$ saturation $\left(\mathrm{SaO}_{2}\right)$, at least when $\mathrm{SaO}_{2}$ is less than $95 \%$. Furthermore, acid-base disturbances have been shown to change the partial pressure at which carbon dioxide begins to stimulate breathing (Duffin 2005). The model simulations presented by this author (Duffin 2005) demonstrated the importance of the central strong ions difference (SID) in the regulation of breathing. Therefore, an altered acid-base balance in response to supra-maximal exercise may also contribute to disturbances in exercise ventilation, $\mathrm{O}_{2}$ transport, and utilisation. Independant of changes in blood $\mathrm{pH}$, increases in blood lactate levels have also been associated with decreases in oxygen supply (Rozier et al. 2007, Mortensen et al. 2007) and $\mathrm{O}_{2}$ extraction (Poole et al. 1994). Therefore, large ionic and metabolic perturbations at the end of exhaustive supra-maximal exercise may affect $\mathrm{O}_{2}$ transport and utilisation and contribute to the end-exercise $\dot{V} \mathrm{O}_{2}$ decrease.

Concomitant with the decrease in $\dot{V} O_{2}$ observed during exercise performed at $\sim 95 \%$ of $\dot{\mathrm{V}} \mathrm{O}_{2 \max }$, Perey et al. (Perrey et al. 2002) observed a decrease in minute ventilation $\left(\dot{V}_{E}\right)$, tidal volume $\left(\mathrm{V}_{\mathrm{T}}\right)$. Hanon \& Thomas (Hanon and Thomas 2011) also reported a strong correlation between the $\mathrm{V}_{\mathrm{T}}$ and $\dot{V} \mathrm{O}_{2}$ responses observed in the last $100 \mathrm{~m}$ of $400-, 800-$, and $1500-\mathrm{m}$ races $(\mathrm{r}=0.85, \mathrm{P}<$ $0.0001)$, suggesting that respiratory response patterns may play a role in the $\dot{V} O_{2}$ decrease during the latter part of supra-maximal exercise. With little increase in alveolar $\mathrm{O}_{2}$ pressure $\left(\mathrm{PAO}_{2}\right)$ during exercise, the pulmonary diffusion capacity becomes critical for the maintenance of arterial $\mathrm{O}_{2}$ pressure $\left(\mathrm{PaO}_{2}\right)$ (Dempsey 2006), and large lungs appear to be an advantage when performing whole-body exercise (Nielsen 2003). On the other hand, large swings in thorax movement could present negative consequences such as excessive fluctuations in intra-thoracic pressures (Amann 2011) or extreme respiratory muscle work and fatigue (Aaron et al. 1992). Indeed, many studies having shown that the respiratory system might affect the quality of the $\mathrm{O}_{2}$ transport during strenuous exercises (Nielsen 2003), it remains to test the contribution of end-exercise respiratory response on the $\dot{V} \mathrm{O}_{2}$ decrease.

The significant $\dot{V} O_{2}$ decline observed in the last two minutes of a 5-10 min exhaustive test (Gonzalez-Alonso and Calbet 2003) has also been directly associated with the inability of the heart to maintain the rate of $\mathrm{O}_{2}$ delivery to locomotive skeletal muscles. These authors emphasised that the mechanisms of fatigue which could explain the declining systemic $\mathrm{O}_{2}$ delivery and $\dot{V} \mathrm{O}_{2}$ during heavy exercise were complex, possibly involving inhibitory signals that originated in different bodily tissues and organs. However, these authors did not concurrently measure changes in respiratory variables, and, further, it is not known if changes in cardiac parameters also contribute to the exercise-induced decrease in $\dot{V} \mathrm{O}_{2}$ during supramaximal exercise lasting less than $2 \mathrm{~min}$. The link between resting lung volumes, exercise-induced cardio-respiratory responses on one hand, and the decrease in $\dot{V} \mathrm{O}_{2}$ on the other, needs to be investigated.

Therefore, the main aims of this study were to identify the primary factors associated with the inability to maintain a high steady-state $\dot{V} \mathrm{O}_{2}$ in healthy, trained subjects. To rule out the potential confounding influence of a decrease in velocity or power output, we chose a constantwork-load cycle exercise. The subjects were tested on a cycle ergometer in order to control the pedalling pattern as participants fatigued (i.e., to avoid a frequency and then a power decrease). We hypothesized that the impairment of both cardiac and respiratory function associated to metabolic perturbations would result in a $\dot{V} \mathrm{O}_{2}$ decrease.

\section{Results}

The results are expressed as the group average, with corresponding statistical results, and for the main physiological variables, as the individual responses referenced as a letter (A to K).

\section{Torque velocity and incremental tests}

Mean values for $\mathrm{P}_{\max }$ and $f_{\text {opt }}$ were $1,318 \pm 191 \mathrm{~W}$ and $121 \pm 7 \mathrm{rpm}$, respectively. $\dot{\mathrm{VO}}_{2 \max }$ and $\mathrm{P}-\dot{\mathrm{V}} \mathrm{O}_{2 \max }$ corresponded to $4.2 \pm 0.7 \mathrm{~L} \cdot \mathrm{min}^{-1}\left(57.9 \pm 6.9 \mathrm{~mL} \cdot \mathrm{min}^{-1} \cdot \mathrm{kg}^{-1}\right)$ and $350 \pm 32 \mathrm{~W}$, respectively. The maximal blood lactate value measured at the end of the incremental test was $13.1 \pm 2.5 \mathrm{mmol} . \mathrm{L}^{-1}$. Maximal CO, SV and HR were $25.1 \pm$

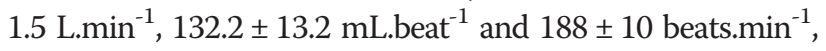
respectively.

\section{Tlim $_{\text {supra }}$ test}

The mean performance for $\mathrm{T}-\mathrm{lim}_{\text {supra }}$ test was $51.4 \pm$ $6.9 \mathrm{~s}$ (range from 43 to $65 \mathrm{~s}$ ). During this test, a mean power $\left(\mathrm{P}_{\text {supra }} \Delta 30 \%\right)$ of $641 \pm 51 \mathrm{~W}$ was sustained at a mean pedalling rate of $109 \pm 6 \mathrm{rpm}$; the mean power output corresponded to $185 \pm 24 \%$ of $\mathrm{P}-\dot{\mathrm{V}} \mathrm{O}_{2 \max }$ and $49 \pm 3.8 \%$ of $\mathrm{P}_{\max }$.

\section{Respiratory responses}

The $\dot{V} O_{2 \text { peak }}$ reached during the Tlim supra $_{\text {sust }}$ test was equal to $55.0 \pm 7.3 \mathrm{~mL} \cdot \mathrm{min}^{-1} \cdot \mathrm{kg}^{-1}\left(95.0 \pm 7.6 \%\right.$ of $\left.\dot{\mathrm{V}} \mathrm{O}_{2 \max }\right)$. Figure 1 displays the time course of the $\dot{V} O_{2}$ expressed relative to time for the eleven subjects. During Tlim supra $_{\text {a }} \dot{V} O_{2 p e a k}$ value was detected at $43.3 \pm 5.3 \mathrm{~s}$ after the onset of the test 


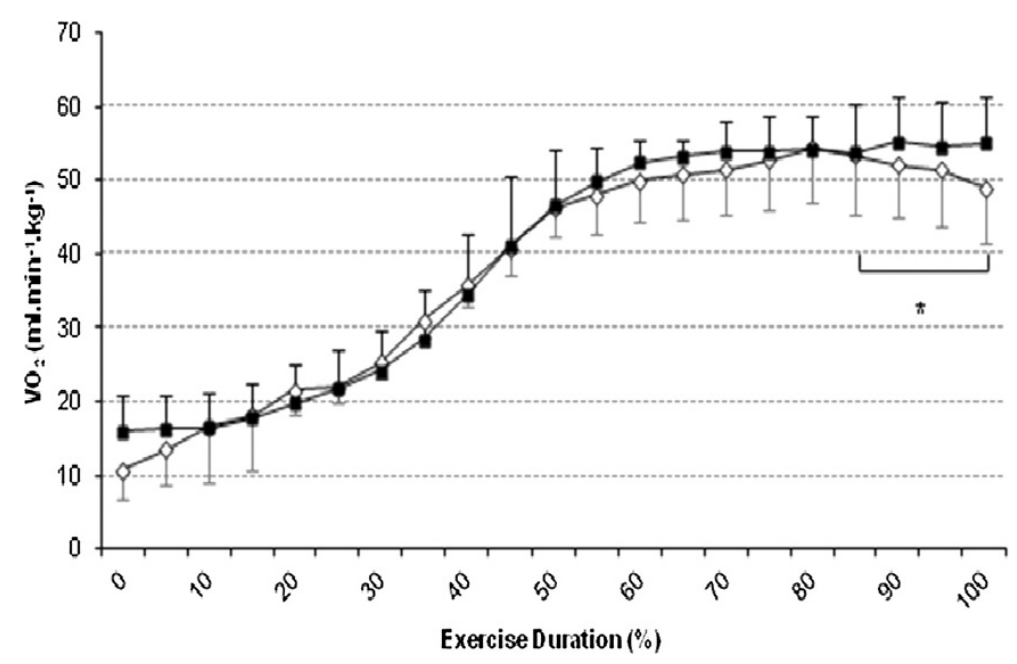

Figure 1 Mean time course of $\dot{\boldsymbol{V}} \boldsymbol{O}_{2}$ during the Tlim ${ }_{\text {supra }}$ test in the decrease and no decrease subjects. Time course of oxygen uptake during the $\operatorname{Tlim}_{\text {supra }}$ test at each $5 \%$ interval-duration in the subjects who present a $\leq 5 \%$ (white labels) and $>$ (black labels) $\dot{V} \mathrm{O}_{2}$ decrease Values are mean $\pm \mathrm{SD}^{*}{ }^{*}$ : significant decrease relative to $\dot{\mathrm{V}} \mathrm{O}_{2 \text { peak }}, \mathrm{P}<0.05$.

( $\sim 80 \%$ of the total test duration). From $80 \%$ of the total duration until the end of the test, average mean $\dot{V} \mathrm{O}_{2}$ for the group, significantly decreased by $5.4 \pm 4.7 \%$ of the $\dot{V} O_{2 \text { peak }}$ $(P<0.05)$. The peak $\mathrm{VRMO}_{2}$ value observed at the end of the exercise was $423.9 \pm 96.7 \mathrm{~mL} \cdot \mathrm{min}^{-1}$. This corresponded to $11.9 \pm 2.1 \%$ (ranged from 8.6 to $15.0 \%$ ) of the whole pulmonary oxygen uptake.

In 6 of our 11 subjects (subjects A, B, C, D, E, F in Figure 2), the decrease in $\dot{V} \mathrm{O}_{2}$ was greater than $5 \%$, corresponding to $9.1 \pm 2.4 \%$ of peak values. In the 5 other subjects (G, H, I, J, K), the decrease was between zero and $3.5 \%(0.9 \pm 2.0 \%)$.

During the Tlim $\mathrm{supra}_{\text {su }}$, considering the peak $(2.6 \pm 0.5 \mathrm{~L})$ and final values $(2.4 \pm 0.4 \mathrm{~L})$, a global decrease in $\mathrm{V}_{\mathrm{T}}$ corresponding to $5.9 \pm 5.6 \%$ was found $(P<0.05)$ with no concomitant global decrease in $\mathrm{RF}$ and $\dot{V}_{E}$. This $\mathrm{V}_{\mathrm{T}}$ decrease was observed in 7 subjects (Figure 2), whereas a decrease in RF and in $\dot{V}_{E}$ (not presented in Figure 2)

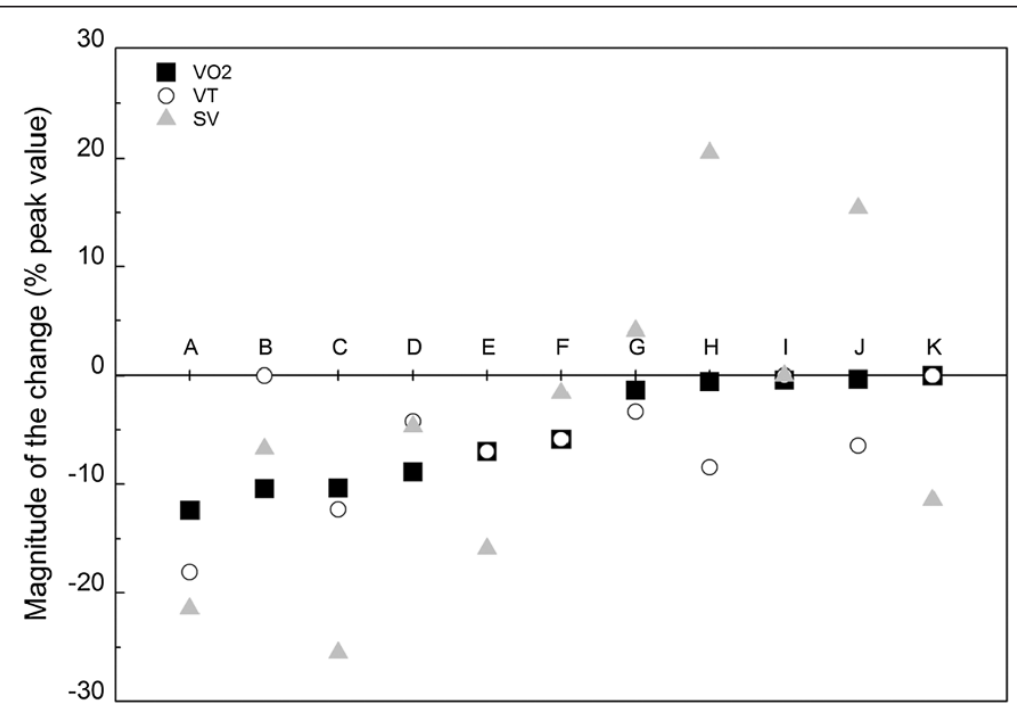

Figure 2 Magnitude of the $\dot{\boldsymbol{V}} \boldsymbol{O}_{2}, \mathrm{~V}_{\mathbf{T}}$, SV changes in the eleven subjects during the Tlim supra test. $\dot{V} O_{2}, V_{T}, S V$ are changes (decrease or increase) expressed relatively to peak values observed during the constant-power cycling test ( $\mathrm{Y}$ axis in \%). A, B...... K represent the eleven subjects classified from the greatest (on the left) to the smallest (on the right) $\dot{V} \mathrm{O}_{2}$ decrease. Six subjects (A to F) presented a $>5 \%$ decrease in $\dot{V} \mathrm{O}_{2}$ and/or $\mathrm{SV}$. 
was only observed in one (subject E) and 3 subjects (subjects A, E and J), respectively. The decrease in VT was $7.9 \pm 6.4 \%$ in subjects who present a $\dot{V} O_{2}$ decrease (A to $\mathrm{F}$ ) and $3.5 \pm 3.8 \%$ in subjects $\mathrm{G}$ to $\mathrm{K}$ who present a $<5 \% \dot{V} \mathrm{O}_{2}$ decrease. The difference between these two groups was significant $(P<0.05)$ with an effect size equivalent to 0.80 .

The functional pulmonary data are presented in Table 1. The ICC for the FVC pre-tests was 0.95 (confidence interval: 0.88-0.98). The mean $\mathrm{P}_{\mathrm{ET}} \mathrm{O}_{2}$ peak value was $122.2 \pm$ $4.8 \mathrm{mmHg}$ and VR was $89.8 \pm 10.5 \%$ of the estimated MVV. The difference between the subjects who exhibited a $<$ or $>5 \% \dot{V} \mathrm{O}_{2}$ decrease was significant $(P<0.05)$ for the pre-exercise values of $\mathrm{FEV}_{1}$ with a corresponding effect size equivalent to 2.24 .

The comparison between pre and post-Tlim supra $_{\text {(Figure 3) }}$ data revealed a significant decrease in $\mathrm{FEV}_{25}, \mathrm{FIVC}$ and FVC $(P<0.05)$.

\section{Cardiac responses}

HR values attained a steady-state value of $185 \pm 11$ beats. $\min ^{-1}(98.4 \pm 5.0 \%$ of IT maximal HR). The highest CO $\left(25.0 \pm 5.6 \mathrm{~L} \mathrm{~min}^{-1}\right)$ and SV $(140.3 \pm 33.0 \mathrm{~mL})$

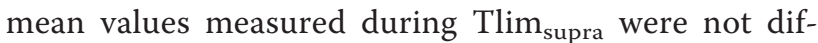
ferent from maximal values recorded during the IT. In 6 out of 11 subjects (A, B, C, D, E and K), a SV decrease of more than $5 \%$ was observed (Figure 2 ).

If we compare the decrease in $\mathrm{SV}$ in those subjects who present a $\dot{V} \mathrm{O}_{2}$ decrease or not, the decrease values in $\mathrm{SV}$ were $17.7 \pm 12.3 \%$ in subjects $\mathrm{A}$ to $\mathrm{F}$ and $3.8 \pm$ $8.4 \%$ in subjects $\mathrm{G}$ to $\mathrm{K}$. The difference between the two groups was significant $(P<0.05)$ with a corresponding effect size equivalent to 1.29 .

Table 1 Mean (SD) spirometric data measured at rest (pre-test) and $3 \mathrm{~min}$ after exercise (post-test)

\begin{tabular}{|c|c|c|c|}
\hline & Pre-test & Post-test & Post-test (\%) \\
\hline FVC & $5.2(0.8)$ & $5.0(0.8) *$ & $96.4(6.0)$ \\
\hline $\mathrm{FEV}_{1}(\mathrm{~L})$ & $4.4(0.6)$ & $4.2(0.7)+$ & $95.5(7.0)$ \\
\hline $\mathrm{FEV}_{1} / \mathrm{FVC}(\%)$ & 85.7 (7.6) & 84.7 (8.9) & $99.2(9.7)$ \\
\hline FIVC (L) & $5.6(0.7)$ & $5.4(0.9) *$ & $96.6(4.7)$ \\
\hline $\mathrm{FIV}_{1}(\mathrm{~L})$ & $5.3(0.6)$ & $4.7(1.3)$ & $90.7(21.0)$ \\
\hline $\mathrm{FEV}_{25}\left({\left.\mathrm{~L} . \mathrm{S}^{-1}\right)}^{-1}\right.$ & $6.6(1.5)$ & $5.2(1.9) *$ & 86.2 (32.6) \\
\hline $\mathrm{FEV}_{50}\left({\left.\mathrm{~L} . \mathrm{S}^{-1}\right)}^{-1}\right.$ & $4.8(0.8)$ & $4.7(1.2)$ & 98.5 (19.5) \\
\hline $\mathrm{FEV}_{75}\left({\left.\mathrm{~L} . \mathrm{S}^{-1}\right)}^{-1}\right.$ & $2.6(0.9)$ & $3.0(1.2)$ & $108.5(32.3)$ \\
\hline
\end{tabular}

*: Significant difference between pre and post test at $P<0.05,+: P=0.08$. Post-test (\%) post-test expressed in \% pre-test, FVC forced vital capacity, FEV forced expiratory volume in $1 \mathrm{~s}, F E V_{1} / F V C$, FIVC forced inspiratory volume, FIV forced inspiratory volume in $1 \mathrm{~s}, F E V_{25}, 50,75$ forced expiratory flow at that point that is 25,50 and $75 \%$ from FVC.

\section{Blood metabolic responses}

The blood results measured before and after Tlim $_{\text {supra }}$ are presented in Table 2. The peak values of [La], $\mathrm{pH}$ and $\left[\mathrm{HCO}_{3}^{-}\right]$were obtained 5 min after the end of the exercise. The $\mathrm{SaO}_{2}$ value measured immediately after stopping exercise was $92.5 \pm 2.7 \%$.

\section{Relationships between the $\dot{\mathrm{V}} \mathrm{O}_{2}$ decrease and metabolic,} respiratory and cardio-dynamic data

The magnitude of the $\dot{V} \mathrm{O}_{2}$ decrease was correlated with the $\mathrm{P}_{\mathrm{ET}} \mathrm{O}_{2}$ peak values $(\mathrm{R}=0.80, \mathrm{P}<0.005)$, and the correlation with the decrease in $V_{T}$ approached significance $(\mathrm{R}=0.57, \mathrm{P}=0.06)$. The magnitude of the $\dot{V} \mathrm{O}_{2}$ decrease was also correlated with $\mathrm{FEV}_{1}(\mathrm{R}=0.72$, $\mathrm{P}<0.005)$ and $\mathrm{FEV}_{25}(\mathrm{R}=0.73, \mathrm{P}<0.01)$ measured at rest and post-exercise, respectively. The partial correlations between $\dot{V} \mathrm{O}_{2}$ on one part and $\mathrm{V}_{\mathrm{T}}, \mathrm{SV}, \mathrm{P}_{\mathrm{ET}} \mathrm{O}_{2}$ and $\mathrm{FEV}_{1}$ on the other part, were 0.52, ( $\left.\mathrm{P}>0.05\right), 0.70$, 0.78 and $0.71(\mathrm{P}<0.05)$, respectively. As observed in Figure 2, 5 of the 6 subjects exhibiting a $\dot{V} \mathrm{O}_{2}$ decrease also presented a SV decrease (expressed as a percentage of the peak value) $\left(8.6 \pm 9.9 \mathrm{~mL}^{\text {.beat }}{ }^{-1}\right)$, but the inverse was not verified with one subject $(\mathrm{K})$ presenting a drop in SV without a $\dot{V} \mathrm{O}_{2}$ decrease. Nevertheless, the relationship between the $\mathrm{SV}$ and $\dot{V} \mathrm{O}_{2}$ decrease was significant $(R=0.75, P<0.01)$. Significant correlations were also observed between SV decrease and both the peak value of $\mathrm{P}_{\mathrm{ET}} \mathrm{O}_{2}(\mathrm{R}=-0.65, \mathrm{P}<0.05)$ and the resting $\mathrm{FEV}_{1}(\mathrm{R}=0.73, \mathrm{P}<0.01)$ as shown in Figure 4. No significant relationships $(P>0.05)$ were observed between the $\dot{V} \mathrm{O}_{2}$ decrease and the blood data $\left([\mathrm{La}](\mathrm{R}=-0.45), \mathrm{pH}(\mathrm{R}=0.10), \mathrm{SaO}_{2} \quad(\mathrm{R}=0.14)\right.$ and $\left[\mathrm{HCO}_{3}^{-}\right](\mathrm{R}=0.24)$.

\section{Discussion}

A significant mean decrease in $\dot{V} \mathrm{O}_{2}$ was observed in the last $20 \%$ of the total exercise duration. This decrease was greater than $5 \%$ of the peak value in 6 out of 11 subjects, with 5 of these 6 subjects also presenting a decrease in stroke volume. The correlations indicated that the magnitude of the $\dot{V} \mathrm{O}_{2}$ decrease was linked with that of SV, and that both were negatively linked with respiratory parameters such as peak exercise end tidal $\mathrm{O}_{2}$ partial pressure and resting forced expiratory volume in $1 \mathrm{~s}$. The strong interrelations between cardiac and respiratory responses suggest that both contribute to the $\dot{V} \mathrm{O}_{2}$ decrease during intense, supramaximal cycling exercise. A significant post-exercise decrease in resting expiratory and inspiratory flow volumes was observed suggesting that there was also respiratory muscle fatigue. 

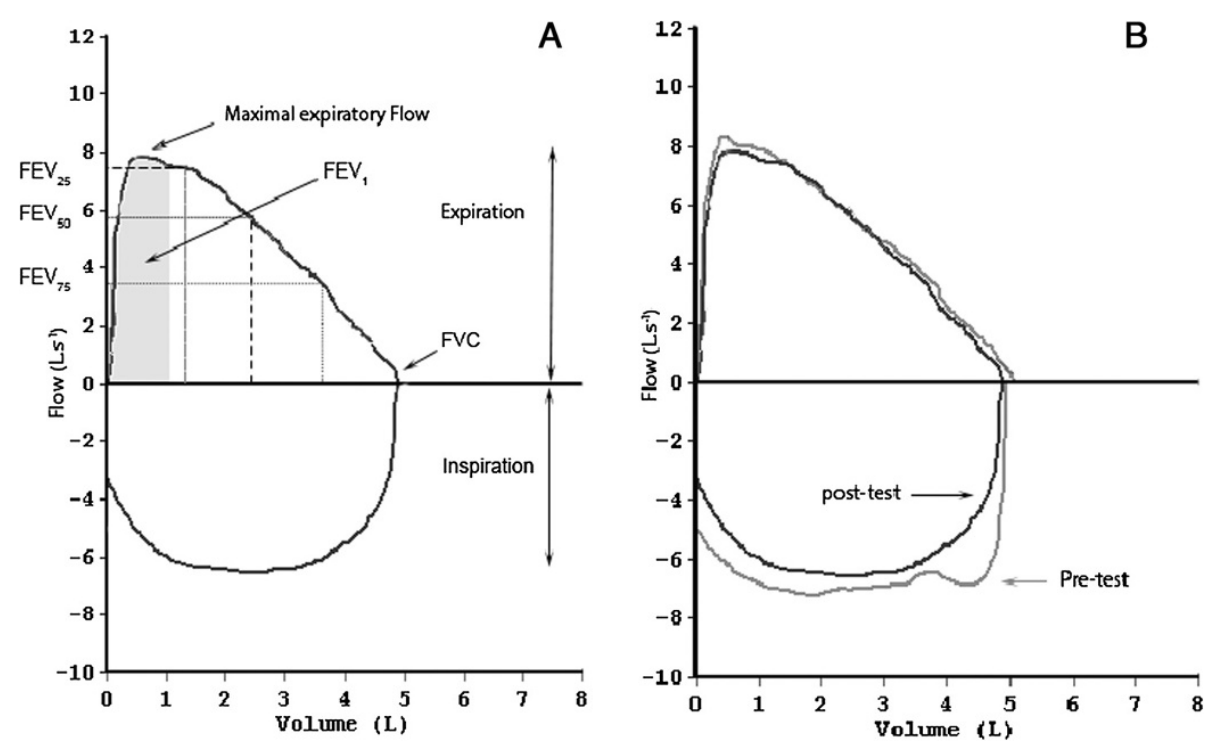

Figure 3 A. Main spirometric parameters recorded during the experimental session, B. Maximal flow-volume loop measured at rest before the Tlim $_{\text {supra }}$ and 3 min after the Tlim supra in subject D. A: FVC: forced vital capacity, FEV 1 : forced expiratory volume in $1 \mathrm{~s}$, FEV $25,50,75$ : forced expiratory flow at that point that is 25,50 and $75 \%$ from FVC. B: in grey and black: maximal flow volume recorded before and after the Tlim supra test, respectively.

\section{$\mathrm{VO}_{2}$ peak}

The present study indicates that during a cycling test performed at $185 \%$ of MAP, well-trained cyclists are able to reach $95 \%$ of their $\dot{\mathrm{V}} \mathrm{O}_{2 \max }$ in less than $50 \mathrm{~s}$. This is similar to the value of $94 \%$ obtained during a $400-\mathrm{m}$ track run (Hanon et al. 2010). As reviewed by Gastin (Gastin 2001), $\dot{V} \mathrm{O}_{2}$ can be as high as $90 \%$ of the athlete's maximum after 30-60 s. However, these previous studies all utilized intensive cycling exercise of short duration and initiated with a maximal starting power (Wingate test or all-out exercise). In the present study, the power was constant, but sufficiently elevated $\left(185 \% \mathrm{P}-\dot{\mathrm{V}}_{2 \max }\right)$ to induce exhaustion in less than $60 \mathrm{~s}$. Therefore, our

Table 2 Mean (SD) values for blood parameters measured during the Tlim supra $_{\text {test }}$

\begin{tabular}{lllll}
\hline & Pre-test & $\mathbf{0}$ & $\mathbf{5}$ min & $\mathbf{8}$ min \\
\hline $\mathrm{SaO}_{2}(\%)$ & $95.2(1.5)$ & $92.5(2.7) *$ & $95.9(1.0) *$ & $95.7(1.2)$ \\
{$[\mathrm{La}]\left(\mathrm{mmol} . \mathrm{L}^{-1}\right)$} & $3.8(1.1)$ & $9.4(3.3) *$ & $15.9(1.7) *$ & $14.9(1.9) *$ \\
$\mathrm{pH}$ & $7.39(0.02)$ & $7.30(0.06) *$ & $7.21(0.04)^{*}$ & $7.24(0.04)^{*}$ \\
{$\left[\mathrm{HCO}_{3}\right]\left(\mathrm{mmol} . \mathrm{L}^{-1}\right)$} & $23.7(1.1)$ & $20.7(2.5) *$ & $12.3(1.8) *$ & $12.4(1.8)$ \\
$\mathrm{paO}_{2}(\mathrm{mmHg})$ & $78.9(9.2)$ & $76.2(15.5) *$ & $99.0(8.5) *$ & $95.9(14.0)$ \\
$\mathrm{paCO}_{2}(\mathrm{mmHg})$ & $38.8(1.6)$ & $42.0(3.1) *$ & $30.7(2.9) *$ & $28.9(2.8) *$ \\
\hline
\end{tabular}

* statistically different from the previous result (post 5 is different from post $0, \ldots$, post 8 from post 5$)$. $P<0.05$.

The blood parameters were collected $1 \mathrm{~min}$ before the test at the end of the warm-up (pre-test), and at 0,5 and $8 \mathrm{~min}$ of passive recovery following the Tlim supra test.

The blood variables are oxygen saturation $\left(\mathrm{SaO}_{2}\right)$, lactate concentration [La] and bicarbonate concentration $\left[\mathrm{HCO}_{3}^{-}\right], \mathrm{pH}$ and partial pressure for $\mathrm{O}_{2}\left(\mathrm{PaO}_{2}\right)$ and $\mathrm{CO}_{2}\left(\mathrm{PaCO}_{2}\right) \cdot \mathrm{n}=11$. protocol was successful at soliciting a large percentage of the $\mathrm{V}_{2 \max }$ during an intense constant-power exercise in well-trained sprint cyclists.

\section{$\dot{\mathrm{V}} \mathrm{O}_{2}$ decrease}

A moderate decrease in the mean $\dot{V} \mathrm{O}_{2}$ was observed during the final $20 \%$ of the supramaximal cycle test. The magnitude of this $\dot{V} \mathrm{O}_{2}$ decrease (0 to 12\%) differed from our recent results obtained during a 400-m running field test of similar duration $(50 \mathrm{~s})$, in which a systematic and greater $\dot{V} \mathrm{O}_{2}$ drop (15\%) was observed in the final $100 \mathrm{~m}$ (Hanon et al. 2010). Of note, and contrary to the present study, this last exercise segment was performed with a large velocity decrease. Nevertheless, a $\dot{V} \mathrm{O}_{2}$ decrease can occur in exercise performed at a constant pace in a subset of subjects, suggesting that at least some of this decrease is independent from a velocity or power decrease (Nummela and Rusko 1995, Perrey et al. 2002). It should be noted that, as in the above-mentioned studies (Hanon et al. 2010), the $\dot{V} O_{2}$ decrease occurred while $\dot{\mathrm{V}} \mathrm{O}_{2 \max }$ was not reached.

Each step in the $\mathrm{O}_{2}$ supply chain, from breathing air to transport to the muscle cells, could influence $\mathrm{O}_{2}$ availability, especially during whole-body, maximalintensity exercise. Although hyperventilation produces an increase in alveolar $\mathrm{O}_{2}$ tension to overcome the diffusion limitation of the lungs (Dempsey 2006), this could also have negative consequences such as extreme energetic cost, respiratory muscle fatigue, or attainment of the respiratory reserve. Each of these factors could have 


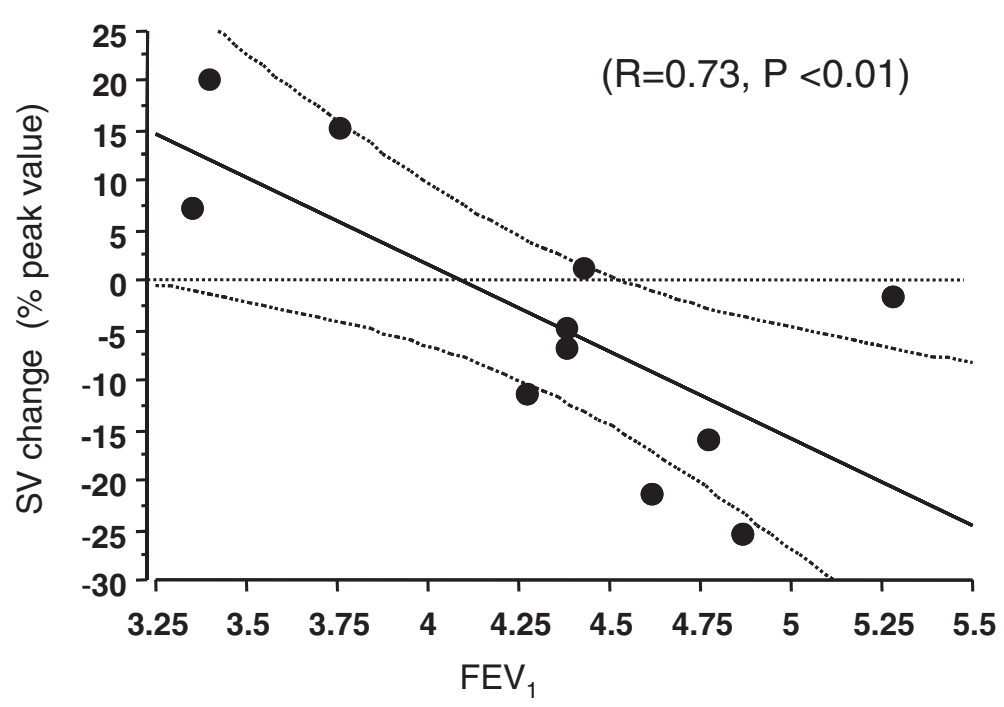

Figure 4 Relationship between the magnitude of the decrease in stroke volume (SV) and the resting forced expiratory volume in $1 \mathrm{~s}$ $\left(F_{E V}\right)$. FEV $1(L)$ : forced expiratory volume in $1 \mathrm{~s}, \mathrm{SV}$ change (\%): stroke volume expressed as a percent of peak value $(r=0.73, P<0.01), n=11$. The broken lines indicate the $95 \%$ confidence intervals.

influenced $\dot{V} \mathrm{O}_{2}$ during the latter stages of our exercise protocol.

\section{Metabolic data and the $\mathrm{V}_{2}$ decrease}

The lack of a relationship between the magnitude of the $\dot{V} \mathrm{O}_{2}$ decrease and the post-test blood changes is not in accordance with our previous all-out running data. In this previous experiment, a 23 and $12 \%$ drop in velocity was observed in the last $100 \mathrm{~m}$ of 400- (Hanon et al. 2010) and 800-m (Hanon and Thomas 2011) races, respectively. The [lactate], $\left[\mathrm{HCO}_{3}^{-}\right]$and $\mathrm{pH}$ were respectively $22.0 \mathrm{mmol} . \mathrm{L}^{-1}$, $<5 \mathrm{mmol} . \mathrm{L}^{-1}$ and 7.00 after the $400-\mathrm{m}$ race, whereas these values were $15.9 \mathrm{mmol} . \mathrm{L}^{-1}$, >12 mmol. $\mathrm{L}^{-1}$ and 7.21 in the present constant-power exercise, indicating a more moderate alteration of the acid-base balance. Therefore, in this context, we can hypothesize that the blood buffers were not completely depleted with the result that, contrary to the running (Hanon et al. 2010), rowing (Nielsen et al. 1999) or cycling (Bishop et al. 2007) all-out exercises, the organism was able to prevent an additional acidosis. In the present study, the post-exercise arterial saturation values $(92.5 \pm 2.7 \%)$ are at the limit of the definition of EIAH (less or equal to $92 \%$ ). The magnitude of the $\dot{V} \mathrm{O}_{2}$ decrease (5.4\%) appears to be in line with the statement that $\dot{V} \mathrm{O}_{2}$ appears to decrease by $2 \%$ for each $1 \%$ decrease of $\mathrm{SaO}_{2}$ under 95\% (Harms et al. 2000). Nevertheless, no significant correlation was observed between the magnitude of the $\dot{V} \mathrm{O}_{2}$ decrease and the present blood $\mathrm{PaO}_{2}$, $\mathrm{SaO}_{2}$ and $\mathrm{pH}$ values. The brief duration of this supramaximal exercise, the type of exercise (constant-power vs all-out), and the chosen sport (cycling vs. running), could explain the lower EIAH values compared to those usually observed in well-trained runners (Millet et al. 2009). These global metabolic results suggest that if the bicarbonate reserve are sufficient to eliminate excess $\mathrm{H}^{+}$, the $\mathrm{O}_{2}$ saturation may not be maximally affected by the eventual decrease in $\mathrm{PaO}_{2}$ (Nielsen 2003) and may not represent a major cause of the decrease in $\dot{V} \mathrm{O}_{2}$.

\section{Respiratory cost and respiratory muscle fatigue}

During a 10-min exercise at $\sim 95 \%$ of $\dot{\mathrm{V}}_{2 \max }$, Perrey et al. (Perrey et al. 2002) observed a significant decrease in $\dot{V}_{E}$ (due to a decrease in $\mathrm{V}_{\mathrm{T}}$ ) in subjects who demonstrated a $\dot{V} \mathrm{O}_{2}$ decrease. In the present supra-maximal exercise, $\dot{V}_{E}$ and RF increased until the end of the exercise, except in two subjects who exhibited a concomitant $\dot{V}_{E}$ and $\dot{V} O_{2}$ decrease. However, the overall significant $\mathrm{V}_{\mathrm{T}}$ decrease (5\%), observed in eight subjects at the end of the test, tended to be correlated with the decrease in $\dot{V} \mathrm{O}_{2} \quad(\mathrm{R}=0.57, \mathrm{P}=0.06, \mathrm{n}=11)$. The maximal $\mathrm{VRMO}_{2}$ values $\left(9-15 \%\right.$ of the whole pulmonary $\left.\dot{V} \mathrm{O}_{2}\right)$, similar to the maximal values previously published (Aaron et al. $1992)$ and the VR values ( $90 \pm 10 \%$ of MVV), could also raise questions about the ability to carry out this ventilatory load. Furthermore, the functional capacity tests demonstrated a decrease in the inspiratory forced cap-

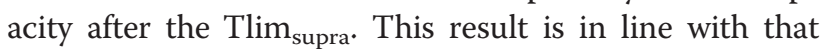
recorded in well-trained rowers (Volianitis et al. 2001), cyclists (Romer et al. 2006) and swimmers (Lomax and McConnell 2003) who experienced a reduction in inspiratory muscle strength immediately after exercise. The magnitude of this decrease in the present study 
(10\%) was less than post 300 - and 400-m swimming (15\%), but this latter measurement was performed $20 \mathrm{~s}$ after the end of the test. Based on the observation that voluntary activation recovers almost fully by $3 \mathrm{~min}$ (Bigland-Ritchie et al. 1986), we chose to collect posttest spirometric data $3 \mathrm{~min}$ after the exercise in order to exclude the hypothesis of a central activation failure. Our data demonstrating a FIVC decrease are in line with the observation of the diaphragm fatigue shown by Johnson et al. (Johnson and Sieck 1993) who stated that near maximal VR values cannot be carried out for more than 15 to $30 \mathrm{~s}$. Therefore, our data confirm that the respiratory muscle response is likely to be affected during constant-power supramaximal exercise.

\section{Respiratory reserve}

Maintaining the $\mathrm{O}_{2}$ alveolar pressure $\left(\mathrm{P}_{\mathrm{A}} \mathrm{O}_{2}\right)$ through the stimulation of the respiratory muscles could cause athletes to reach and even surpass the respiratory reserve during maximal exercise, and a small portion of the maximal exercise flow volume and pressure-volume envelope on expiration could approach maximal expiratory flow limits near end-expiratory lung volume (Johnson et al. 1996). In the present study, only one subject reached the resting VR values and this subject did not exhibit a $\dot{V}$ $\mathrm{O}_{2}$ decrease but, Babb (Babb 2013) stated that expiratory flow limitation is not all or none phenomenon and that approaching maximal expiratory flow can affect breathing mechanics. The onset of dynamic airways compression and subsequent airway resistance start long before expiratory flow becomes limited. Therefore in the last part of the exercise, when near $\dot{\mathrm{V}}{ }_{2 \max }$ values are attained, a number of mechanisms for inadequate hyperventilation are possible (Johnson et al. 1992). Furthermore, based on the demonstration of a modified $\dot{V}_{E}$ response in an inclined versus an upright position (Grappe et al. 1998), we cannot exclude an influence of the inclined cycling position on the ratio between $\dot{V}_{E}$ recorded in the cycling position and the MVV recorded in an upright position.

\section{Cardio-respiratory responses and $\dot{\mathrm{V}} \mathrm{O}_{2}$ decrease}

All subjects who exhibited a decrease in $\dot{V} O_{2}$ also presented a decrease in SV during the exercise, and a correlation was observed between the final SV data and the decrease in $\dot{V} \mathrm{O}_{2}$. The observation that $\mathrm{CO}$ declined significantly before maximal heart rate was reached confirms the results presented by Gonzales-Alonso (Gonzalez-Alonso and Calbet 2003) and indicates that maximal cardiovascular function was attained below maximal heart rate. The decline in stroke volume clearly caused the drop in $\mathrm{CO}$, although the underlying mechanisms remain obscure. The positive correlation between the decrease in $\dot{V} O_{2}$ and $\mathrm{FEV}_{1}$ could indicate that expiratory intrathoracic pressure could have a negative effect on the $\dot{V} \mathrm{O}_{2}$ response. Because the heart and lungs share a common surface area, progressive lung inflation and hyperpnea with exercise may increase competition for intrathoracic space and inhibit cardiac filling via a change in cardiac compliance (Peters et al. 1989). Expiratory load leads to a reduction in CO related to an increase in expiratory abdominal and intrathoracic pressure (Stark-Leyva et al. 2004). Hortop et al. (Hortop et al. 1988) has previously demonstrated, in patients with a cystic fibrosis, a strong relationship between the changes in $\mathrm{SV}$ with exercise and the $\mathrm{FEV}_{1}$. In our trained subjects, the decrease in SV was significantly correlated with $\mathrm{P}_{\mathrm{ET}} \mathrm{O}_{2}$ and $\mathrm{FEV}_{1}$, which could corroborate the relationship reported between SV and changes in intrathoracic pressure following voluntary lung inflation (Stark-Leyva et al. 2004) and the findings of a recent overview emphasizing the respiratory mechanisms that impair $\mathrm{O}_{2}$ transport (Amann 2011). In those subjects with high levels of expiratory flow, we could suggest that, in inclined cycling position, positive expiratory intrathoracic pressure is greater, increasing the ventricular afterload and reducing the rate of ventricular filling during diastole (Miller et al. 2007, Stark-Leyva et al. 2004) which could be deleterious for the maintenance of SV (Amann 2012) and therefore $\dot{V} \mathrm{O}_{2}$.

\section{Conclusions}

We demonstrated that a $\dot{V} O_{2}$ decrease occurs at the end of a constant-power supra-maximal exercise in 6/11 subjects, with the main result being that this phenomenon was related to respiratory characteristics and to the cardiac response. The relationship between stroke volume and $\dot{V} \mathrm{O}_{2}$ decrease confirms, for supramaximal exercise, previous observations for longer and less intensive cycling exercise (Gonzalez-Alonso and Calbet 2003), (Mortensen et al. 2008). Furthermore, the influence of the respiratory system on the $\dot{V} \mathrm{O}_{2}$ response observed during the exercise in the participants who present both high resting forced expiratory volume and exercise peak $\mathrm{P}_{\mathrm{ET}} \mathrm{O}_{2}$ are innovative and confirm that the pulmonary system is a key determinant of the physiologic responses before stopping a supramaximal cycling exercise. The present data suggest that the respiratory response in case of acute maximal exercise could be the origin of the decrease in SV and $\dot{V} \mathrm{O}_{2}$ in cycling position. The relation between respiratory, cardiac parameters and $\dot{V} \mathrm{O}_{2}$ decrease in the case of acute acidosis remains to be tested, and we can hypothesize that different mechanisms may be involved in the $\dot{V} O_{2}$ decrease depending on the level of acidosis and the body position. 


\section{Methods}

Fourteen specifically trained subjects were solicited for this study. They had at least 5 years of competitive cycling experience and trained 8 hours per week in sprint track cycling and/or BMX. All were successful at nationallevel events and none had any history of pathology of the lower-limb muscles or joints.

Three subjects were not retained in data processing because of signal loss in the collection of ventilatory data or non observance of the given pedalling rate. Then, eleven trained men (age 24.9 $\pm 6.5 \mathrm{y}$, height $1.79 \pm$ $0.05 \mathrm{~m}$ and body mass $75.3 \pm 8.2 \mathrm{~kg}$ ) volunteered for this study. They were informed of the nature of the study, and the possible risks and discomforts associated with the experimental procedures, before giving their written consent to participate. The experimental design of the study was approved by the local Ethics Committee of Saint-Germain-en-Laye (France; acceptance n'2009-A0100453), and was carried out in accordance with the Declaration of Helsinki.

\section{Experimental protocol}

The protocol, carried out during the pre-competition period, included two sessions separated by two days: (1) a first session consisting of anthropometric measurements, resting spirometric monitoring (volume and flow), a torque-velocity cycling test, and an incremental test performed until exhaustion on a calibrated cycle ergometer, (2) a second session consisting of a constantload, supra-maximal cycle test performed until exhaustion; in a pilot study, we observed that the body temperature was not increased by more than $1^{\circ} \mathrm{C}$ during this test.

During the first visit, anthropometric data were recorded, subjects were familiarized with the spirometric tests to be performed in this study, and three resting spirometric tests were recorded in order to test the reliability of the measures (Figure 3). Subjects began with a warm-up of $15 \mathrm{~min}$ of cycling at 100-150 W, $1 \mathrm{~min}$ of recovery and a 5-s sprint. After a 5-min recovery, participants were asked to perform three maximal cycling sprints ( $5 \mathrm{~s}$ separated by $3 \mathrm{~min}$ of recovery) according to a previous protocol (Dorel et al. 2010). Three different resistive torques of $0,0.4-0.7,1-1.5 \mathrm{Nm} / \mathrm{kg}$ body mass were applied to obtain maximal force and power values over a large range of pedaling rates among the three bouts. After computation, the data from the three sprints were used to draw force- and power-velocity relationships and hence to determine maximum power $\left(\mathrm{P}_{\max }\right)$ and the corresponding specific optimal pedaling rate $\left(f_{\text {opt }}\right)$ at which $\mathrm{P}_{\max }$ occurred (for details, see (Dorel et al. 2010)).

After 20 min of rest, they performed an incremental cycle test (IT) to determine their $\dot{\mathrm{V}} \mathrm{O}_{2 \max }$ and power output at $\dot{\mathrm{V}} \mathrm{O}_{2 \max }\left(\mathrm{P}-\dot{\mathrm{V}} \mathrm{O}_{2 \max }\right.$, i.e. the power that elicited $\dot{\mathrm{V}} \mathrm{O}_{2 \max }$ ). The progressive protocol consisted of 6 min of pedaling at $100 \mathrm{~W}$ followed by a stepped ramp increase in power output of $20 \mathrm{~W} \cdot \mathrm{min}^{-1}$ until volitional exhaustion. Participants were instructed to maintain their chosen preferred cadence for as long as possible, and the test was completed when the cadence fell more than $10 \mathrm{rpm}$ below this value for more than $5 \mathrm{~s}$ despite strong verbal encouragement. All respiratory and cardiac variables were recorded continuously.

During the second session, subjects were asked to perform a standard warm-up: $8 \mathrm{~min}$ at $150 \mathrm{~W}, 2 \mathrm{~min}$ at $260 \mathrm{~W}$, a recovery period (i.e., $2 \mathrm{~min}$ ), a 10 -s sprint of progressively increasing intensity with the last $3 \mathrm{~s}$ performed at a maximal all-out intensity, $90 \mathrm{~s}$ of recovery and finally two brief all-out sprints ( $5 \mathrm{~s}$ in duration) interspersed with $90 \mathrm{~s}$ of recovery. After a further 10 minutes of passive recovery, subjects performed the cycling exercise (Tlim supra $_{\text {a }}$ ) at a constant power output $\left(\mathrm{P}_{\text {supra }} \Delta 30 \%\right)$ for as long as possible until exhaustion. $\mathrm{P}_{\text {supra }} \Delta 30 \%$ was defined as the supra-maximal intensity above MAP corresponding to an increment of $30 \%$ of the difference between $P_{\max }$ (estimated from torque-velocity test) and $\mathrm{P}-\dot{\mathrm{V}} \mathrm{O}_{2 \max }$ $\left(\mathrm{P}_{\text {supra }} \Delta 30 \%=\mathrm{P}-\dot{\mathrm{V}} \mathrm{O}_{2 \max }+\left[0.3 \times\left(\mathrm{P}_{\max }-\mathrm{P}-\dot{\mathrm{V}} \mathrm{O}_{2 \max }\right]\right)\right.$. Subjects were required to keep a constant pedalling rate (i.e., corresponding to $f_{\text {opt }}$ minus $10 \%$ ). No information relative to test duration was given to the subjects. The test continued until complete exhaustion: either until the cyclists voluntarily chose to stop the exercise or until they were no longer able to maintain their initial test cadence $( \pm 3 \mathrm{rpm})$, which was considered as a failure to maintain the required task (i.e., the target power output at a constant cadence). Respiratory and cardiac responses were recorded continuously during the entire experimental session. Arterialised capillary blood samples $(85 \mu \mathrm{L})$ were taken from a hyperemized ear-lobe just before the start of $\operatorname{Tlim}_{\text {supra }}$ (7 min after the end of the warm-up), at exhaustion, and 5 and 8 min during the passive recovery.

\section{Material and data collection/processing}

All testing sessions took place in a well-ventilated laboratory at a temperature of $20-22^{\circ} \mathrm{C}$ and were conducted using an electronically-braked cycle ergometer (Excalibur Sport, Lode, Groningen, The Netherlands). Vertical and horizontal positions of the saddle, handlebar height, crank and stem lengths were set to match the most comfortable and usual position of the participants.

\section{Respiratory responses}

Spirometric variables, [i.e. forced vital capacity (FVC), forced expiratory volume in $1 \mathrm{~s}\left(\mathrm{FEV}_{1}\right)$, Tiffeneau index (FEV/FVC), forced inspiratory volume (FIVC) forced inspiratory volume in $1 \mathrm{~s}\left(\mathrm{FIV}_{1}\right)$, forced expiratory flow at 
that point that is 25,50 or $75 \%$ from $\mathrm{FVC}\left(\mathrm{FEV}_{25}, 50\right.$ or 75$)$ ] (Figure 2A) were measured with an ergospirometric device (Spirobank II, MIR, Roma, Italy) before and $3 \mathrm{~min}$

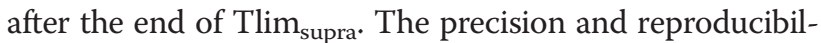
ity of the data $\left(\mathrm{FEV}_{1}\right.$ and $\mathrm{FVC}$ ) have been reported (Liistro

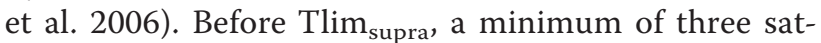
isfactory inspiratory and expiratory efforts were conducted with the highest measurement being defined as maximal. At the end of the Tlim supra $_{\text {, and due to time- }}$ constraints (recovery influence), only one satisfactory measurement was asked to the subjects in order to measure the exercise-induced changes in the respiratory function.

During both IT and Tlim supra $_{V} \mathrm{~V}_{2}, \dot{V}_{E}, \mathrm{CO}_{2}$ production $\left(\dot{V} \mathrm{CO}_{2}\right)$, respiratory frequency $(\mathrm{RF}), \mathrm{V}_{\mathrm{T}}$ and endtidal oxygen tension $\left(\mathrm{P}_{\mathrm{ET}} \mathrm{O}_{2}\right)$ were recorded breath by breath with a fixed gas exchange system (Quark CPET, Cosmed, Roma, Italy). Calibration of the gas analyser was performed according to the manufacturer's instructions before each test for each subject. To avoid artefacts in recording signals, the finger was warmed with a vasodilator ointment 10-15 min before starting the measurement. The apparatus was automatically calibrated before each test. During the IT, breath-by-breath gas exchange values were smoothed (i.e., 3-s central moving average). In order to characterize the subjects, the highest $\dot{V} \mathrm{O}_{2}$ value in a 30-s period was considered as the $\dot{\mathrm{V}} \mathrm{O}_{2 \max }$. The criteria used for the determination of $\dot{\mathrm{V}}_{2 \max }$ were threefold: a plateau in $\dot{V} \mathrm{O}_{2}$ despite an increase in power output, a respiratory exchange ratio (RER) above 1.1, and a heart rate (HR) above $90 \%$ of the predicted maximal HR. For the purpose of comparing, over the same period of sampling, with the peak value of $\dot{V} O_{2}\left(\dot{V} O_{2 p e a k}\right)$ measured during Tlim $_{\text {supra, }}$ the highest 5-s average was also determined. To determine $\dot{V} O_{2 p e a k}$ during $\mathrm{Tlim}_{\text {supra }}$ (and as previously reported (Hanon et al. 2010)), values were smoothed (i.e. 3-s central moving average) and then a 5-s average was applied in order to compare $\dot{V} \mathrm{O}_{2}$ and other ventilatory responses $\left(\mathrm{V}_{\mathrm{T}}, \mathrm{RF}, \dot{V}_{E}\right)$, with those of cardiac output (CO), stroke volume (SV) and changes in $\mathrm{SaO}_{2}$ at the same time.

For Tlim supra $_{\text {, the }} \dot{V} \mathrm{O}_{2}$ value $\left(\dot{V} O_{2 e n d}\right)$ was defined as the average during the last 5-s period and the $\dot{V}$ $\mathrm{O}_{2}$ decrease was considered as $\dot{V} \mathrm{O}_{2 p e a k}-\dot{V} \mathrm{O}_{2 e n d}$. The $\dot{V} \mathrm{O}_{2}$ decline was considered as a $\dot{V} \mathrm{O}_{2}$ decrease, when the magnitude of the phenomenon was larger than $5 \%$ of the peak value while the power of exercise continued to be above $\mathrm{P}-\dot{\mathrm{V}} \mathrm{O}_{2 \max }$ (Billat et al. 2009). The same criterion was applied to the other cardio-respiratory variables.

The $\dot{V} \mathrm{O}_{2}$ of the respiratory muscles $\left(\mathrm{VRMO}_{2}\right.$, expressed in $\mathrm{mL} \cdot \mathrm{min}^{-1}$ ), was calculated from the work of breathing $\left(\mathrm{W}_{\mathrm{B}}\right.$, kg.min $\left.{ }^{-1}\right)$ using the equation proposed by Coast et al. (Coast et al. 1993):

$$
\begin{gathered}
\mathrm{W}_{\mathrm{B}}=-0.251+0.0382 \dot{V}_{E}+0.00176 \dot{V}_{E^{2}}, \\
\text { and } \mathrm{VRMO}_{2}=34.9+7.45 W_{B} .
\end{gathered}
$$

The ventilatory reserve (VR) was defined as $\dot{V}_{E}$ expressed as a percent of the estimated resting MVV (maximal voluntary ventilation):

$$
\dot{V}_{E} \div M V V \text {, where } M V V=\text { rest FEV } V_{1} \times 40
$$

(Johnson et al. 1996).

\section{Cardiac responses}

A bio-impedance method was used to determine SV, HR and CO (Physioflow, Manatec Type PF05L1, Strasbourg, France). The basis for this technique and its application, validity and reliability for exhaustive exercise testing have been described (Lepretre et al. 2004), and it has been demonstrated that thoracic hyperinflation does not alter CO (Charloux et al. 2000). For this experiment, SV, $\mathrm{HR}$ and $\mathrm{CO}$ values were averaged every five seconds.

\section{Blood metabolic responses}

Prior to, 0 and $3 \mathrm{~min}$ post-IT, blood samples were collected and analysed for lactate concentration using a Lactate Pro analyser (Arkray, Japan). Prior to and postTlim $_{\text {supra }}$ session, arterialised capillary blood samples $(85 \mu \mathrm{L})$ were analysed to measure blood $\mathrm{pH}$, [La], $\mathrm{SaO}_{2}$, $\mathrm{PaO}_{2}$ and $\mathrm{CO}_{2}\left(\mathrm{PaCO}_{2}\right)$ and bicarbonate concentration $\left(\left[\mathrm{HCO}_{3}^{-}\right]\right)$with an i-STAT dry chemistry analyser (Abbott, Les Ulis, France).

\section{Statistical analysis}

Data are reported as mean \pm SD. Because subjects did not perform exactly the same exercise duration, data were expressed relative to the \% of total duration (every

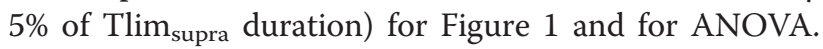

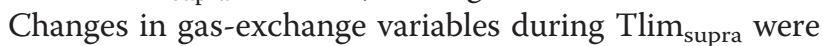
evaluated by a one-way analysis of variance (ANOVA), with repeated-measures across each 5\% interval, followed by multiple comparisons (Student-Newman-Keuls) to test the effect of time on the variables. The intra-class correlation (ICC) was calculated for pre-test spirometric data. Relationships between variables (ventilatory, cardiodynamic, arterial oxygen saturation, metabolic parameters and $\dot{V} \mathrm{O}_{2}$ ) at different times of the test and final Tlimsupra performance were analyzed by a Pearson's correlation coefficient. In order to measure the strength of the relationship between the $\dot{V} \mathrm{O}_{2}$ decrease and a given variable, while controlling the effect of the other variables, Pearson partial correlations were also calculated. The level of significance was set at $P<0.05$. Finally, aiming to 
compare the difference in main variables, between the subject who exhibited a $>5 \%$ decrease in $\dot{V} \mathrm{O}_{2}$ and the others, effect sizes (ES) were calculated using Cohen's $d$. Effect sizes of 0.8 or greater, around 0.5 and 0.2 or less were considered as large, moderate, and small, respectively. The level of significance was set at $P<0.05$.

\section{Competing interests}

The authors declare that they have no competing interests.

\section{Authors' contribution}

$\mathrm{CH}$ and $\mathrm{CT}$ conceived of the study and carried out the experimental design, participated in acquisition of data (respiratory and metabolic data). $\mathrm{CH}$ drafted the manuscript and performed the statistical analysis. SD had substantial contributions to conception and design (cycling procedure) and managed the cycling performance analysis. RDP performed the acquisition and analysis of the cycling data. PML carried out the acquisition and analysis of the cardiac data. JDB substantially helped in the draft of the manuscript and participated in acquisition of the data. SP revised the manuscript and participated in acquisition, analysis and interpretation of data. All authors read and approved the final manuscript.

\section{Acknowledgement}

The authors are grateful to the French Ministry of Health, Youth and Sport for their financial support, the Doctor C. Palierne for his medical assistance and P. Arnal for his technical assistance. The authors warmly thank the subjects involved in this study for their trust and availability.

\section{Author details}

${ }^{1}$ French National Institute of Sports (INSEP), Research Department, Laboratory of Sport, Expertise and Performance, 11 Tremblay Avenue, 75012 Paris, France. 2Laboratory "Motricité, Interactions, Performance" (EA 4334), University of Nantes, F-44000 Nantes, France. ${ }^{3}$ University of Picardie Jules Verne (EA-3300), 80025 Amiens cedex, France. ${ }^{4}$ Movement to Health (M2H), Montpellier-1 University, Euromov, Montpellier, France. ${ }^{5}$ Institute of Sport, Exercise and Active Living (ISEAL), and the College of Sport and Exercise Science, Victoria University, Melbourne, Australia. 'STAPS Department, University of Evry Val d'Essonne, François Mitterrand Boulevard 91025, Evry, France.

Received: 10 September 2013 Accepted: 18 November 2013 Published: 5 December 2013

\section{References}

Aaron EA, Seow KC, Johnson BD, Dempsey JA (1992) Oxygen cost of exercise hyperpnea: implications for performance. J Appl Physiol 72:1818-1825

Amann M (2011) Central and peripheral fatigue: interaction during cycling exercise in humans. Med Sci Sports Exerc 43:2039-2045

Amann M (2012) Pulmonary system limitations to endurance exercise performance in humans. Exp Physiol 97:311-318

Babb TG (2013) Exercise ventilatory limitation: the role of expiratory flow limitation. Exerc Sport Sci Rev 41:11-18

Bigland-Ritchie B, Furbush F, Woods JJ (1986) Fatigue of intermittent submaximal voluntary contractions: central and peripheral factors. J Appl Physiol 61:421-429

Billat V, Hamard L, Koralsztein JP, Morton RH (2009) Differential modeling of anaerobic and aerobic metabolism in the 800-m and 1,500-m run. J Appl Physiol 107:478-487

Bishop D, Edge J, Thomas C, Mercier J (2007) High-intensity exercise acutely decreases the membrane content of MCT1 and MCT4 and buffer capacity in human skeletal muscle. J Appl Physiol 102:616-621

Charloux A, Lonsdorfer-Wolf E, Richard R, Lampert E, Oswald-Mammosser M, Mettauer B, Geny B, Lonsdorfer J (2000) A new impedance cardiograph device for the non-invasive evaluation of cardiac output at rest and during exercise: comparison with the "direct" Fick method. Eur J Appl Physiol $82: 313-320$

Coast JR, Rasmussen SA, Krause KM, O'Kroy JA, Rhodes J (1993) Ventilatory work and oxygen consumption during exercise and hyperventilation. J Appl Physiol 74:793-798
Dempsey JA (2006) Is the healthy respiratory system (always) built for exercise? J Physiol 576:339-340

Dorel S, Couturier A, Lacour JR, Vandewalle H, Hautier C, Hug F (2010) Force-velocity relationship in cycling revisited: benefit of two-dimensional pedal forces analysis. Med Sci Sports Exerc 42:1174-1183

Duffin J (2005) Role of acid-base balance in the chemoreflex control of breathing. J Appl Physiol 99:2255-2265

Gastin PB (2001) Energy system interaction and relative contribution during maximal exercise. Sports Med 31:725-741

Gonzalez-Alonso J, Calbet JA (2003) Reductions in systemic and skeletal muscle blood flow and oxygen delivery limit maximal aerobic capacity in humans. Circulation 107:824-830

Grappe F, Candau R, Busso T, Rouillon JD (1998) Effect of cycling position on ventilatory and metabolic variables. Int J Sports Med 19:336-341

Hanon C, Thomas C (2011) Effects of optimal pacing strategies for 400-, 800-, and 1500-m races on the VO2 response. J Sports Sci 29:905-912

Hanon C, Lepretre PM, Bishop D, Thomas C (2010) Oxygen uptake and blood metabolic responses to a 400-m run. Eur J Appl Physiol 109:233-240

Harms CA, McClaran SR, Nickele GA, Pegelow DF, Nelson WB, Dempsey JA (2000) Effect of exercise-induced arterial $\mathrm{O} 2$ desaturation on VO2max in women. Med Sci Sports Exerc 32:1101-1108

Hortop J, Desmond KJ, Coates AL (1988) The mechanical effects of expiratory airflow limitation on cardiac performance in cystic fibrosis. Am Rev Respir Dis 137:132-137

Johnson BD, Sieck GC (1993) Differential susceptibility of diaphragm muscle fibers to neuromuscular transmission failure. J Appl Physiol 75:341-348

Johnson BD, Saupe KW, Dempsey JA (1992) Mechanical constraints on exercise hyperpnea in endurance athletes. J Appl Physiol 73:874-886

Johnson BD, Aaron EA, Babcock MA, Dempsey JA (1996) Respiratory muscle fatique during exercise: implications for performance. Med Sci Sports Exerc 28:1129-1137

Lepretre PM, Koralsztein JP, Billat VL (2004) Effect of exercise intensity on relationship between VO2max and cardiac output. Med Sci Sports Exerc 36:1357-1363

Liistro G, Vanwelde C, Vincken W, Vandevoorde J, Verleden G, Buffels J (2006) Technical and functional assessment of 10 office spirometers: A multicenter comparative study. Chest 130:657-665

Lomax ME, McConnell AK (2003) Inspiratory muscle fatigue in swimmers after a single 200 m swim. J Sports Sci 21:659-664

Miller JD, Smith CA, Hemauer SJ, Dempsey JA (2007) The effects of inspiratory intrathoracic pressure production on the cardiovascular response to submaximal exercise in health and chronic heart failure. Am J Physiol Heart Circ Physiol 292:H580-H592

Millet GP, Vleck VE, Bentley DJ (2009) Physiological differences between cycling and running: lessons from triathletes. Sports Med 39:179-206

Mortensen SP, Gonzalez-Alonso J, Damsgaard R, Saltin B, Hellsten Y (2007) Inhibition of nitric oxide and prostaglandins, but not endothelial-derived hyperpolarizing factors, reduces blood flow and aerobic energy turnover in the exercising human leg. J Physiol 581:853-861

Mortensen SP, Damsgaard R, Dawson EA, Secher NH, Gonzalez-Alonso J (2008) Restrictions in systemic and locomotor skeletal muscle perfusion, oxygen supply and VO2 during high-intensity whole-body exercise in humans. J Physiol 586:2621-2635

Nielsen HB (2003) Arterial desaturation during exercise in man: implication for $\mathrm{O} 2$ uptake and work capacity. Scand J Med Sci Sports 13:339-358

Nielsen HB, Boushel R, Madsen P, Secher NH (1999) Cerebral desaturation during exercise reversed by $\mathrm{O} 2$ supplementation. Am J Physiol 277:H1045-H1052

Nummela A, Rusko H (1995) Time course of anaerobic and aerobic energy expenditure during short-term exhaustive running in athletes. Int I Sport Med 16:522-527

Perrey S, Candau R, Millet GY, Borrani F, Rouillon JD (2002) Decrease in oxygen uptake at the end of a high-intensity submaximal running in humans. Int J Sport Med 23:298-304

Peters J, Fraser C, Stuart RS, Baumgartner W, Robotham JL (1989) Negative intrathoracic pressure decreases independently left ventricular filling and emptying. Am J Physiol 257:H120-H131

Poole DC, Gladden LB, Kurdak S, Hogan MC (1994) L-(+)-lactate infusion into working dog gastrocnemius: no evidence lactate per se mediates VO2 slow component. J Appl Physiol 76:787-792

Romer LM, Lovering AT, Haverkamp HC, Pegelow DF, Dempsey JA (2006) Effect of inspiratory muscle work on peripheral fatigue of locomotor muscles in healthy humans. J Physiol 571:425-439 
Rozier MD, Zata VJ, Ellsworth ML (2007) Lactate interferes with ATP release from red blood cells. Am J Physiol Heart Circ Physiol 292:H3038-H3042

Stark-Leyva KN, Beck KC, Johnson BD (2004) Influence of expiratory loading and hyperinflation on cardiac output during exercise. J Appl Physiol 96:1920-1927

Thomas C, Hanon C, Perrey S, Le Chevalier JM, Couturier A, Vandewalle H (2005) Oxygen uptake response to an 800-m running race. Int J Sports Med 26:268-273

Volianitis S, McConnell AK, Koutedakis Y, McNaughton L, Backx K, Jones DA (2001) Inspiratory muscle training improves rowing performance. Med Sci Sports Exerc 33:803-809

doi:10.1186/2193-1801-2-651

Cite this article as: Hanon et al:: Prevalence of cardio-respiratory factors in the occurrence of the decrease in oxygen uptake during supra-maximal, constant-power exercise. SpringerPlus 2013 2:651.

Submit your manuscript to a SpringerOpen ${ }^{\circ}$ journal and benefit from:

- Convenient online submission

- Rigorous peer review

- Immediate publication on acceptance

- Open access: articles freely available online

- High visibility within the field

- Retaining the copyright to your article 